\title{
AGENTES ESTRESSORES NO TRABALHO E SUGESTÕES PARA AMENIZÁ-LOS: OPINIÕES DE ENFERMEIROS DE PÓS-GRADUAÇÃO
}

\section{STRESSORS AGENTS IN WORKPLACE AND SUGESTIONS TO SOFTEN ITS: OPINIONS OF THE POST GRADUATION'S NURSES}

\author{
Luciana Monteiro Mendes Martins* \\ Jeane A. G. Bronzatti** \\ Carmem Silvia de Campos A. Vieira** \\ Silvia Helena Baffi Parra** \\ Yara Boaventura da Silva**
}

MARTINS, L. M. M. et al. Agentes estressores no trabalho e sugestões para amenizá-los: opiniões de enfermeiros de pós-graduação. Rev.Esc.Enf.USP, v. 34, n. 1, p. 52-8, mar. 2000.

\section{RESUMO}

A sobrecarga de trabalho, relacionamento e comunicação, características da Instituição e poluição ambiental foram os agentes estressores organizacionais mais citados neste estudo composto por 30 enfermeiras, sendo que a melhoria no planejamento do trabalho, o aspecto de humanização, adequação dos recursos humanos, melhora na comunicação $e$ educação continuada, dentre outras, foram as sugestões identificadas para melhorar estes agentes estressores. Como agentes estressores extra organizacionais, os mais citados foram problemas econômicos e familiares e distância do trabalho / transporte.

PALAVRAS-CHAVE: Estresse. Trabalho. Enfermeiro.

\section{ABSTRACT}

The work overload, relationship and comunication problems, institution's characteristics and ambiental pollution were the stressing organization agents with the greatest pontuation in this study composed by 30 nurses. The work planning, work humanization, suitable human resourses, improving comunication and continued education were the suggestions given by nurses to minimize these stressing organizational agents. Analysing the stressing extra organizational agents, economic and familiar problems, work distance and transportation to work, were the most pointed.

KEYWORDS: Stress. Work. Nurse.

\section{INTRODUÇÃO}

O estresse é um termo que parece estar na moda nos dias de hoje. Sempre encontramos pessoas reclamando de estresse ou que estão passando por uma situação estressante ou que tal notícia as deixou estressadas. Afinal, o que vem a ser estresse? Segundo o dicionário Aurélio ${ }^{6}$, estresse é um conjunto de reações do organismo a agressões de diversas origens, capazes de perturbar-lhe o equilibrio interno.

O estresse está presente diariamente em nossas vidas, desde a execução de tarefas simples do cotidiano,até aquelas mais complexas, as quais exigem maior demanda fisica e emocional, podendo nos expor ao risco de graves doenças. Segundo BERNARDINO $^{2}$, o estresse pode desencadear muitas patologias fisicas e mentais, implicando em sérias alterações no ambiente de trabalho como problemas de relacionamento interpessoal, absenteísmo, acidentes e insatisfação no trabalho.

PRESTON, IVANCEVICH, MATTESON15, conceituam estresse como sendo uma resposta

Enfermeira do Hosp. Prof. Edmundo Vasconcelos, Mestranda da Escola de Enfermagem da Universidade de São Paulo_Email: 1meades@nutecnet.com.br

Enfermeira Mestranda da Escola de Enfermagem da Universidade de São Paulo. 
adaptativa, mediada por características individuais ou processos psicológicos, sendo uma conseqüência a qualquer evento externo que identifica demandas físicas ou psicológicas em um indivíduo. LIMA ${ }^{11}$ comenta que o estresse ocorre quando a capacidade de adaptação do indivíduo é suplantada por eventos e sobrecargas emocionais muitas vezes no aspecto qualitativo, sendo quantitativamente insignificantes e, na maioria das vezes decorre de excessos e tensões emocionais no âmbito afetivo, familiar, profissional e/ou social, sendo que as respostas e sintomatologia dependem da personalidade de cada indivíduo.

O estresse relacionado ao trabalho resulta de várias situações em que a pessoa percebe este ambiente como ameaçador às suas necessidades de realização pessoal e profissional, prejudicando sua interação com suas funções e com o ambiente de trabalho, na medida em que este ambiente contém demandas excessivas a ela, ou que ela não contenha recursos adequados para enfrentar tais situações ${ }^{7}$.

Portanto, estresse no trabalho é o resultado de um conjunto de várias situações ou condições, que são potencialmente desestabilizadoras em razão de incongruências ou falta de adaptação entre pessoas e ambiente $^{13}$

Um estudo a respeito do nivel de estresse no trabalho de enfermeiras americanas que atuam em saúde pública e hospitais, mostrou que os agentes estressores mais citados foram a administração da unidade de enfermagem, o relacionamento interpessoal e os cuidados com o paciente. Outros agentes estressores citados, apesar de baixa freqüência, foram: conhecimento e habilidade da equipe, acompanhantes/ familiares e planta fisicas.

HAWLEY10 em seu estudo sobre fontes de estresse para enfermeiras de unidades de emergência no Canadá, identificou como agentes estressores o desenvolvimento de recursos humanos, as recompensas, as urgências, a comunicação e o estilo de supervisão. Outros fatores de estresse encontrados neste estudo foram a baixa média de idade da equipe de enfermagem e médicos, o uso inadequado do departamento de emergência, treinamento dos médicos que não gostam de receber conselhos de enfermeiras experientes em emergência, longa espera de especialista durante o plantão, dificuldade de comunicação entre médico e paciente, demora na transferência de pacientes, inefetividade para melhorar o ambiente de trabalho, dificuldade de comunicação e entendimento, incompetência, inexperiência, condições deficientes de trabalho e planta fisica inadequada.

No Brasil alguns estudos têm sido realizados nesta área. TAKAHASHI 17 ao detectar as fonte de estresse emocional que afetam as enfermeiras que trabalham na assistência à criança grave, identificou como fontes extrínsecas de estresse emocional, o contexto de UTI (ambiente e finalidade), os aspectos administrativos, a equipe de UTI, a família e a condição da criança. Como fontes intrínsecas, a condição pessoal do enfermeiro e alguns aspectos relativos à questão da morte.

$\mathrm{COSTENARO}^{4}$ et al, ao avaliarem a rotatividade de pessoal em um hospital estadual obtiveram como principais motivos de saídas, os de ordem financeira, vida social restrita e jornada de trabalho (40 horas).

PONTES ${ }^{14}$, numa pesquisa sobre o trabalho noturno do enfermeiro, concluiu que o seu significado é de grande importância, pois é considerado muito estressante, cansativo e desgastante, sendo o repouso importante e necessário, o qual, na maioria das vezes, ocorre somente após o plantão. O repouso também existe informalmente e de modo geral, em condições consideradas humilhantes. $\mathrm{O}$ auto cuidado destes enfermeiros já está comprometido pelo fato de trabalharem à noite e agravado pela necessidade de possuírem outro emprego durante o dia.

CHAVES $^{3}$, num estudo elaborado com enfermeiros do turno noturno, investigou a influência de algumas características individuais no ajustamento e no enfrentamento do estresse causado pelo trabalho e encontrou que o estado de sono atual piora à medida que os escores de traço de ansiedade ou padrão de comportamento para o estresse, ou ainda a disposição para atividades aumentam; o estado de saúde piora à medida que o escore para os traços de ansiedade ou idade forem maiores; a presença de sintomas de estresse aumenta conforme aumentam os escores para traço de ansiedade (pessoas mais ansiosas) ou para padrão de comportamento para o estresse (pessoas mais vulneráveis a estressores).

ROCHA; GUARAGM; BETTOM 16 - ao pesquisarem a existência de resistência por parte da equipe de enfermagem do Centro de Terapia Intensiva em assistir pacientes conscientes, encontraram os motivos que levam os funcionários a preferir pacientes inconscientes: a gravidade dos pacientes e o maior número de cuidados faz com que o tempo passe mais depressa e torne o plantão mais suportável; os pacientes conscientes são muitos solicitantes (e solicitações não são prioritárias).

- Segundo DEJOURS 5 , a forma de que se reveste o sofrimento varia com o tipo de organização do trabalho. Contra a angústia do trabalho, assim como contra a insatisfação, os operários elaboram estratégias defensivas, de maneira que o sofrimento não é imediatamente identificável. Assim, disfarçado ou mascarado, o sofrimento só pode ser revelado através de uma capa própria a cada profissão, que constitui de certa forma sua sintomatologia.

O sofrimento mental não pode ser considerado apenas como uma conseqüência deplorável, mais em certos casos, propicio à produtividade; e a exploração do corpo passa sempre por uma neutralização prévia da vida mental, através da organização do trabalho. É 
preciso compreender que as resistências individuais acompanham resistências coletivas, no centro das quais se encontram as coletivas de profissão 5 .

Concluímos então, que existem inúmeros fatores estressantes no trabalho, os quais agem individualmente em diferentes proporções, conforme a estrutura psicológica e física da enfermeira. MALONEY ${ }^{12}$ mostrou que as enfermeiras de unidades de internação apresentam maior nível de estresse do que as que trabalham em unidade criticas; isto porque elas têm uma maior contato com o paciente e sua família, quando comparadas à enfermeiras de unidades críticas. Quando morre um de seus pacientes, elas sentem como se estivessem perdido um amigo.

De acordo com PRESTON, IVANCEVICH, MATTESON 15 , existem os estressores organizacionais - iluminação, ruídos, sobrecarga de serviço, papel conflitante, problemas no grupo, características da organização; e os estressores extra organizacionais relacionamento familiar, problemas econômicos, distância do local de trabalho.

Percebendo as diferentes fontes e agentes estressantes para o profissional enfermeiro, decidimos então realizar este trabalho, o qual possui os seguintes objetivos:

- Verificar os agentes estressores organizacionais dos enfermeiros do curso de pós-graduação da Escola de Enfermagem da Universidade de São Paulo que além de estudar, trabalham;

- Identificar as sugestões destes enfermeiros para minimizar estes agentes estressores organizacionais.

- Verificar os agentes estressores extra organizacionais que interferem nos organizacionais.

\section{MÉTODO}

Trata-se de um estudo descritivo-exploratório. Segundo $\mathrm{GIL}^{8}$, a pesquisa descritiva tem como objetivos a descrição das características de determinada população, com a utilização de técnicas padronizadas de coleta de dados, como por exemplo, o questionário. Este mesmo autor descreve uma pesquisa exploratória como sendo aquela que tem como objeto principal, o aprimoramento de idéias ou a descoberta de intuições, envolvendo levantamento bibliográfico e entrevistas com pessoas que tiveram experiências práticas com $o$ problema pesquisado.

A população abrangeu os enfermeiros do curso de pós-graduação da Escola de Enfermagem da Universidade de São Paulo, do ano de 1998, que cursavam as disciplinas Stress, coping e trabalho; Investigação aplicada à saúde do adulto; Fundamentos de enfermagem II; Perspectivas do ensino de enfermagem.
Fizeram parte da amostra, os enfermeiros que, além de cursarem a pós-graduação, desempenhavam atividades profissionais, estavam presentes em sala de aula no dia estipulado para a coleta de dados e que se dispuseram a participar espontaneamente da pesquisa.

A coleta de dados foi realizada pelas próprias autoras, no mês de setembro de 1998, através de um instrumento elaborado previamente pelas mesmas, o qual continha uma definição sobre agentes estressores organizacionais e extra organizacionais, dados de identificação, e três perguntas abertas onde eram questionados quais os agentes estressores organizacionais do trabalho deste enfermeiro, sugestões para amenizá-los, e quais os agentes extra organizacionais que interferiam nos organizacionais.

\section{RESULTADOS E DISCUSSÕES}

Fizeram parte da amostra 30 enfermeiros, sendo a maioria do sexo feminino (90\%). A idade variou entre 24 e 51 anos, prevalecendo a faixa etária de 30 a 39 anos (46,7\%), seguida das faixas de 40 a 49 anos $(30,0 \%)$ e 20 a 29 anos $(16,7 \%)$.

Com relação ao estado civil, 56,7\% eram casados, $40,0 \%$ solteiros e $3,3 \%$ descasados.

O tempo de formado e experiência profissional foram equivalentes, variando de 1 ano e 9 meses a 30 anos, onde $33,4 \%$ correspondeu a faixa de 15 a 20 anos incompletos, seguido de $23,3 \%$ correspondendo a faixa de 10 a 15 anos incompletos, $20 \%$ entre 20 e 30 anos incompletos, $13,3 \%$ de 1 a 5 anos incompletos e $10 \%$ entre 5 e 10 anos incompletos.

Verificamos que $32,3 \%$ destes enfermeiros atuavam em Unidade de Internação (U.I.), 29,0\% na área de Ensino, 16,2\% pertenciam a setores fechados como Unidade de Terapia Intensiva (U.T.I.) e Centro Cirúrgico (C.C.), 6,5\% trabalhavam em Saúde Coletiva e o restante, 12,0\%, em outras áreas como Comissão de Controle de Infecção Hospitalar (CCIH), Resgate, Psiquiatria e Obstetrícia. Tivemos 01 resposta em branco, o que correspondeu a $3,2 \%$.

Com relação ao turno de trabalho, a maioria pertencia ao turno diurno $(80,0 \%)$ e apenas $20,0 \%$ trabalhava em sistema de rodízio de turno, ou seja, trabalhavam diurno e noturno.

A carga horária trabalhada semanalmente correspondeu, em grande massa, a faixa entre 30 e 60 horas $(86,6 \%)$, sendo $43,3 \%$ entre 30 e 39 horas e $43,3 \%$ na faixa de 40 horas e mais. Também verificamos que $10 \%$ destes enfermeiros trabalhavam entre 10 e 19 horas e 3,4\% de 20 a 29 horas semanais. Na faixa de 30 a 39 horas/semana predominaram enfermeiros atuantes em área hospitalar. 
Quadro 1 - Agentes estressores organizacionais citados pelos enfermeiros de pós - graduação da EEUSP, que trabalham. São Paulo, 1998.

\begin{tabular}{l|c|c}
\hline \multicolumn{1}{c|}{ Agentes estressores organizacionais } & N $^{\circ}$ de citações & \% de enfermeiros \\
\hline - sobrecarga de trabalho & 22 & 73,3 \\
- relacionamento e comunicação & 14 & 46,7 \\
- caracteristicas da instituição & 13 & 43,3 \\
- poluição ambiental & 11 & 36,7 \\
- papel conflitante / relações de poder & 7 & 23,3 \\
- falta de pessoal & 7 & 23,3 \\
- dificuldade de planejamento & 5 & 16,7 \\
- carga horária / rodízio de turno & 5 & 16,7 \\
- ambiente fechado / espaço fisico & 5 & 16,7 \\
- tipo de patologia atendida & 5 & 16,7 \\
- politica salarial & 4 & 13,3 \\
- redução de custos na organização / desemprego & 4 & 13,3 \\
- falta de estimulo / reconhecimento profissional & 4 & 13,3 \\
- falta de educação continuada & 3 & 10,0 \\
- insatisfação / impotência profissional & 3 & 10,0 \\
- dificuldades para aceitar mudanças & 2 & 6,7 \\
- competitividade negativa & 1 & 3,3 \\
- não possui agentes estressores organizacionais & 1 & 3,3 \\
\hline
\end{tabular}

Analisando as respostas da primeira pergunta sobre a identificação dos agentes estressores organizacionais, 22 enfermeiros $(73,3 \%)$ citaram a sobrecarga de trabalho, abrangendo sobrecarga de atividades propriamente dita, demanda de pacientes, dobra de plantões, excesso de alunos para estágio, trabalho cansativo, demanda excessiva de exigências, poucas folgas. Segundo ARAÚJO ${ }^{1}$, como a enfermeira convive diariamente com uma equipe subordinada a ela, a qual, muitas vezes, é constituída por profissionais pouco qualificados e em número insuficiente, acaba se expondo constantemente a situações de estresse, pois sua supervisão será intensificada e suas atividade ultrapassarão seus limites máximos, sendo ainda responsabilizada pela precariedade da assistência de enfermagem, recebendo críticas de outros profissionais de saúde. Na verdade, esta desqualificação profissional, de acordo com DEJOURS ${ }^{5}$, trata-se mais da imagem de si que repercute do trabalho, pois o individuo fica mais honroso se a tarefa for mais complexas. Também, como o enfermeiro não tem muito bem definido, para si próprio, bem como para a equipe com quem trabalha, o seu papel profissional, na prática acaba assumindo um número excessivo de atividades, das quais muitas delas não são de sua competência e acaba exposto à situações estressantes , as quais poderão acarretar doenças'.

Com relação a problemas de relacionamento e comunicação, obtivemos 14 citações, representando $46,7 \%$ dos enfermeiros estudados, dentre elas problemas com o grupo, desunião, relacionamento interpessoal, relações tumultuadas, problemas pessoais, conflitos com a equipe médica, desrespeito ao ser humano. Vários autores ${ }^{9,10,13,15}$, em estudos realizados com enfermeiras de U.I. , Emergência e Saúde Coletiva, também identificaram o relacionamento interpessoal como sendo um importante agente estressor organizacional, tanto em razão de incongruências e falta de adaptação entre as pessoas, como dificuldade da própria comunicação entre o grupo.

O terceiro item mais citado, com 13 respostas $(43,3 \%$ dos enfermeiros), foi com relação às características da Instituição, abrangendo a pouca resolutividade, mudanças na organização do trabalho, estresse organizacional e institucionalização, pressão da Instituição, cobranças sem propósito, falta de filosofia de trabalho, falta de qualidade organizacional, controles "mesquinhos" , falta de valorização do trabalho que o profissional executa, política administrativa do hospital e da chefia, falta de clareza nos objetivos da organização e do serviço de enfermagem.

DEJOURS 5 , em sua obra "A loucura do trabalho" cita que, até mesmo indivíduos dotados de uma sólida estrutura psíquica podem ser vítimas de uma paralisia mental induzida pela organização do trabalho. E não são tanto as exigências mentais e psíquicas do trabalho que fazem surgir o sofrimento: este começa quando a relação homem/organização do. trabalho está bloqueada. 
A falta de valorização gera um sentimento de inutilidade, remetendo à falta de qualificação e de finalidade do trabalhos. Um estilo de supervisão autoritário, arbitrário, onde o ritmo, as opiniões e necessidades dos funcionários são totalmente, ou quase que totalmente desconsiderados, com falta de diálogo e excesso de feedback negativo, sem nenhuma assistência para os problemas identificados, ocasionam o estresse organizacional, acarretando em insatisfação, baixa da produtividade e qualidade, e insatisfação do trabalhador e da própria instituição.

Com relação à poluição ambiental, ou seja, ruídos, mudanças de temperatura e iluminação, tivemos 11 respostas, correspondendo a $36,7 \%$. A saúde fisica e condições de trabalho são claramente apontados pelos trabalhadores como fonte de perigo para o corpo, sobretudo as condições quimicas e fisicas do trabalho como vapores, pressões, gases tóxicos, ruídos e diferenças de temperaturas. Em um trabalho feito com enfermeiras de U.T.I., o barulho, campainhas de telefones, perguntas excessivas de pessoal recém chegado no setor, alarmes de bombas de infusão, monitores e respiradores, contribuem muito para o estresse organizacional ${ }^{18}$.
Outros agentes estressores organizacionais citados pelos enfermeiros foram: papel conflitante e falta de pessoal (23,3\% cada); carga horária, ambiente fechado/espaço físico, tipo de patologia atendida e dificuldade de planejamento $(16,7 \%$ cada); redução de custos na organização/desemprego, falta de estímulo/ reconhecimento profissional e política salarial $(13,3 \%$ cada); educação continuada e insatisfação/impotência profissional $(10,0 \%$ cada); dificuldade para aceitar mudanças $(6,6 \%)$; competitividade negativa e "sem agentes estressores" (3,3\%). FRANÇA; RODRIGUES' citam como fatores estressantes no trabalho, a liderança autoritária, a execução de tarefas sob pressão, o excesso de serviços e a carência de autoridade e de orientação; sendo a incerteza, um poderoso fator de estresse, sentimento freqüente em nossa sociedade, comumente ligada ao trabalho. Incerteza da manutenção do emprego, do salário, angústia que ameaça aquilo que só se conseguiu com muito esforço e sofrimento.

Com relação à segunda pergunta relacionada às sugestões para amenizar os agentes organizacionais, obtivemos as respostas detalhadas no quadro abaixo.

Quadro 2 - Sugestões para amenizar os agentes estressores organizacionais, citadas pelos enfermeiros de pós - graduação da EEUSP, que trabalham. São Paulo, 1998.

\begin{tabular}{l|c|c}
\hline \multicolumn{1}{c|}{ Sugestões } & $\mathbf{N}^{\circ}$ de citações & \% de enfermeiros \\
\hline - planejamento do trabalho & 12 & 40,0 \\
- humanização no trabalho & 9 & 30,0 \\
- recursos humanos adequados & 9 & 30,0 \\
- melhora da comunicação & 8 & 26,7 \\
- educação continuada & 7 & $26 ; 7$ \\
- planta fisica e condições ambientais adequadas & 4 & 23,3 \\
- horário fixo e redução da carga horária & 4 & 13,3 \\
- conciliação de atividades profissionais e pessoais & 4 & 13,3 \\
- politica salarial & 2 & 13,3 \\
- reconhecimento profissional / autonomia & 2 & 6,7 \\
- transparência organizacional & 1 & 6,7 \\
- redefinição do papel do enfermeiro & 1 & 3,3 \\
- avaliação da assistência & 1 & 3,3 \\
- melhora das condições de trabalho & 1 & 3,3 \\
- respeito ao organograma & 1 & 3,3 \\
- alimentação alternativa & 1 & 3,3 \\
- uso de terapias alternativas & 1 & 3,3 \\
- administração participativa & 1 & 3,3 \\
- ignorar os agentes estressores & 1 & 3,3 \\
- melhorar a politica de saúde coletiva & 1 & 3,3 \\
- minimizar as barreiras cirúrgicas & & 3,3 \\
- não existem soluções individuais para uma instituição & 1 & 3,3 \\
que apresenta quase todos os agentes estressores organizacionais & 1 & 3,3 \\
- em branco & &
\end{tabular}

Verificamos que 40,0\% dos enfermeiros sugeriram melhorar o planejamento do trabalho, redistribuindo o agendamento de pacientes, melhorando a distribuição de serviços e dimensionamento de pessoal, elaborando programas participativos e de avaliação de qualidade de assistência, realizando protocolos, diminuindo o número 
de reuniões e reorganizando o trabalho. Com relação à humanização do trabalho e melhoria dos recursos humanos, tivemos 9 citações em cada uma destas sugestões, significando respostas de $30,0 \%$ dos enfermeiros para cada sugestão. Empatados, em terceiro lugar, tivemos a melhora da comunicação e necessidade de uma educação continuada, ambas com 8 citações $(26,7 \%)$, seguidas de melhoria na planta fisica e condições ambientais (23,3\%); horário fixo / redução da carga horária semanal, conciliação das atividades profissionais e pessoais, e politica salarial (13,3\% cada); reconhecimento profissional / autonomia e transparência organizacional (6,7\% cada). Com apenas 1 citação, significando 3,3\% dos enfermeiros para cada sugestão, foram sugeridos: redefinição do papel do enfermeiro, avaliação da assistência, melhora das condições de trabalho, respeito ao organograma, alimentação alternativa, uso de terapias alternativas, administração participativa, melhorar a política de saúde coletiva, minimizar as barreiras cirúrgicas, ignorar os agentes estressores. Apenas um enfermeiro respondeu que não existem soluções para que os agentes sejam minimizados. Houve uma resposta em branco.

Comparando as respostas das duas primeiras questões, isto é, a identificação dos agentes estressores organizacionais e as sugestões para que estes agentes sejam amenizados, percebemos que existe uma preocupação para que realmente diminua a sobrecarga de trabalho, melhorando seu planejamento e os recursos humanos, juntamente com a ajuda de uma Educação Continuada, proporcionando uma reciclagem da equipe e, como conseqüência, a melhoria da qualidade da assistência prestada ao paciente. ARAÚJO' comenta que a falta de tempo do enfermeiro para executar treinamentos em serviço e a não disponibilidade e viabilidade para a liberação da equipe de enfermagem para ser submetida aos treinamentos e reciclagens, resulta na ineficiência da Educação continuada, dificultando a melhora da qualificação profissional.

Dando ênfase à qualificação profissional, o trabalhador terá condições de competir no mercado de trabalho atual, melhorando sua auto-estima. Com os profissionais melhor preparados, competentes e qualificados, as empresas terão que rediscutir sua política salarial para manter estes profissionais prestando serviços para seu cliente. Segundo ARAÚJO ${ }^{1}$, os salários dos profissionais foram equiparados sem que houvesse a valorização do tempo e de serviço.

Além disto, os enfermeiros sugeriram que houvesse uma melhora, tanto na planta fisica quanto nas condições ambientais, melhorando, portanto, as condições de trabalho.

A necessidade de humanização no trabalho e conseqüente melhora na comunicação e relacionamento interpessoal também garante uma melhoria na qualidade da assistência prestada.

Redução na carga horária semanal e horário fixo de trabalho foram sugestões citadas pelos enfermeiros. Analisando nossa população, sendo a maioria mulheres e casadas, não podemos nos esquecer da multiplicidade de papéis: esposa, mãe, profissional, estudante, mulher.

Na terceira e última questão, identificamos quais os agentes extra organizacionais interferiam nos organizacionais, e obtivemos as seguintes respostas, ilustradas no quadro abaixo:

Quadro 3 - Agentes estressores extra organizacionais que interferem sobre os organizacionais, citados pelos enfermeiros de pós - graduação da EEUSP, que trabalham. São Paulo, 1998.

\section{Agentes estressores extra organizacionais}

- problemas econômicos

- problemas familiares

- distância do trabalho / transporte

- problemas pessoais

- política de saúde

- multiplicidade de papéis

- sobrecarga de atividades extra organizacionais

- falta de lazer

- doença

- resposta inadequada

- não possui agentes estressores extra organizacionais

- mercado de trabalho

- globalização

- relacionamento individual

- violência

- em branco

\begin{tabular}{c|r}
$\mathbf{N}^{\circ}$ de citaçõs & \% de \\
17 & 56,7 \\
16 & 53,3 \\
9 & 30,0 \\
3 & 10,0 \\
3 & 10,0 \\
2 & 6,7 \\
2 & 6,7 \\
2 & 6,7 \\
2 & 6,7 \\
2 & 6,7 \\
2 & 6,7 \\
1 & 3,3 \\
1 & 3,3 \\
1 & 3,3 \\
1 & 3,3 \\
1 & 3,3
\end{tabular}


Analisando o quadro acima percebemos que os problemas econômicos $(56,7 \%)$, problemas familiares $(53,3 \%)$ e distância do trabalho / transporte $(30,0 \%)$ foram os agentes estressores extra organizacionais que influenciam sobre os organizacionais, mais citados pela população estudada.

FRANÇA; RODRIGUES ${ }^{7}$ identificam a incerteza como um poderoso fator de estresse, sendo um dos sentimentos mais freqüentes em nossa sociedade, estando, quase sempre, ligada ao trabalho. Incerteza da manutenção do emprego, do salário, a angústia que ameaça aquilo que só se conseguiu com muito esforço e sofrimento.

Existe uma dificuldade, mas também uma necessidade de se conciliar as atividades pessoais com as profissionais. Não podemos nos esquecer da saúde do trabalhador, da importância de se ter lazer e diversão, de uma alimentação adequada, exercícios fisicos regulares e tempo para a família e para o repouso.

\section{CONCLUSÕES E CONSIDERAÇÕES FINAIS}

A sobrecarga de trabalho, relacionamento e comunicação, as características da instituição e a poluição ambiental foram os agentes estressores organizacionais mais citados pela população estudada, a qual sugeriu a melhoria do planejamento do trabalho, humanização no trabalho, adequação dos recursos humanos, melhora da comunicação e educação continuada, entre outras, como sugestões para amenizar estes agentes. Como agentes estressores extra organizacionais que influenciam sobre os organizacionais, foram citados problemas econômicos, familiares e distância do trabalho / transporte, entre outros.

Chamou-nos a atenção o fato de que o salário foi pouco citado em termos de agente estressor organizacional, e quando analisamos os agentes estressores extra organizacionais influenciadores nos organizacionais, problemas econômicos foram citados por mais da metade da população estudada. Também esperávamos encontrar, como agente estressor extra organizacional, a dificuldade de conciliação entre trabalho e pós-graduação, porém, talvez pelo fato de ser a pós-graduação uma atividade prazeirosa, não foi cotada como estressante.

Segundo DEJOURS 5, "A liberdade não se dá; ela se conquista. O mesmo acontece com relação à organização do trabalho. E provável que não exista solução ideal e que, aqui como em tudo mais, seja sobretudo, a evolução como portadora de esperança. Considerando o lugar dedicado ao trabalho na existência, a questão é saber que tipo de homem a sociedade fabrica através da organização do trabalho. Entretanto, o problema não é, absolutamente, criar novos homens, mas encontrar soluções que permitiriam pôr fim à desestruturação de um certo número deles pelo trabalho".

\section{BIBLIOGRAFIA}

1- ARAÚJO, M.A. Organização da assistência de enfermagem: a consulta de enfermagem no contexto da prática de enfermagem. Brasilia, ABEn, 1991. (Série Documento, 1)

2 - BERNARDINO, E.G. Stress laboral: como controlar. Enfermagem, n.1, p.34-7, 1988.

3 - CHAVES, E.C. Stress e trabalho do enfermeiro: a influência de características individuais no ajustamento e tolerância do turno noturno. São Paulo, 1993. 125p. Tese (Doutorado) Escola de Enfermagem, Universidade de São Paulo.

4 - COSTEnARO, O. M.V. et al Rotatividade de pessoal: causas, conseqüências e propostas. Rev Paul Enf. v.7, n. 1, p. 40-3, 1987.

5 - DEJOURS, C. A loucura do trabalho - estudo de psicologia do trabalho. 5. ed. São Paulo, Cortez, 1992.

6 - FERREIRA, A.B.H. Dicionário Aurélio da língua portuguesa. Nova Fronteira, Rio de Janeiro, Nova Fronteira, 1993.

7 - FRANÇA, A.C.L.; RODRIGUES, A.L. Stress e trabalho - guia básico com abordagem psicossomática. São Paulo, Atlas, 1997.

8 - GIL, A.C. Como elaborar projetos de pesquisa. $2^{\text {a }}$ ed, São Paulo, Atlas, 1989. cap.4, p.45-62: como classificar as pesquisas?

9 - HACHÉ-FAULKNER, N.H.; MACKAY, R.C. Stress in the workplace: public health and hospital nurses. Can. Nurse, v.81, n.4, p. 40-7, 1985.

10 - HAWLEY, M.P. Sources of stress for emergency nurses in four urban Canadian emergency departments. J. Emerg. Nurs., v. 18, n.3, p.211-6, 1992.

11 -LIMA, D.R. Manual de farmacologia clínica, terapêutica e toxicologia. Rio de Janeiro, Guanabara Koogan, 1993.

12 - MALONEY, J.P. Job stress and its consequences on a group of intensive care and nonintensive care nurses. Adv.Nurs.Sci., v.4, n.2, p. 31-42, 1982.

13 - NORBECK, J.S. Types and sources of social support for managing job stress in critical care nursing. Nurs. Res. , v.34, n.4, p.225-30, 1985.

14 - PONTES, Z. O trabalho noturno do enfermeiro: busca de significados sobre o repouso antes, durante e após o plantão. Rev.Bras. Enf., v. 45, n. 1, p. 80-7, 1992.

15- PRESTON, C.A.; IVANCEVICH, J.M.; MATTESON, M.T. Stress and the OR nurse. AORN J., v.33, n.4, p.662-71, 1981.

16 - ROCHA, V.K.; GUARAGM, A. ;BETTOM, A. Pesquisando a existência de resistência por parte da equipe de enfermagem do CTI em assistir pacientes conscientes. Rev Gaúcha Enf., v. 17, n. 2, p. 132-9, 1996.

17 - TAKAHASHI, E.I.U. As fontes de estresse emocional que afetam a enfermeira na assistência à criança grave. Rev. Esc. Enf. USP., v. 19, n. 1, p. 5-20, 1985.

18 - VENINGA, R. Administrator burnout - causes and cures. IN: McCONNELL, E.A. Burnout in the nursing proffession: coping strategies, causes and costs. London, MOSBY, 1982. p.200-18. 